\title{
REVIEW
}

\section{Social differences in traffic injury risks in childhood and youth - a literature review and a research agenda}

\author{
L Laflamme, F Diderichsen
}

\begin{abstract}
Objectives-The paper reviews the scientific literature concerning social differences in traffic injuries in childhood in order to highlight the current state of knowledge and to draw the main lines of a research agenda.

Method-A conceptual framework is used that identifies the mechanisms through which social context, social position, and various exposures may interact in the determination of health inequalities. It is used as a frame for presenting the evidence accumulated so far concerning social differences in traffic injury in childhood, including pedestrian, cyclist, and vehicle passenger injuries.

Results-For most types of traffic injuries, mortality and morbidity are often higher among children from lower social positions and in more deprived socioeconomic areas. Whether the greater occurrence of injuries in deprived areas is a phenomenon attributable to the areas themselves, or merely a reflection of a wider pattern of injuries affecting lower socioeconomic groups, is unclear. There is evidence of an interaction effect between age and gender, and also between socioeconomic status and gender.

Conclusions-The mechanisms leading to social inequalities in traffic injuries in childhood deserve greater scrutiny in future research. Further theoretical developments and empirical investigation will help define intervention needs and enable more effective targeted, long term prevention.
\end{abstract}

(Injury Prevention 2000;6:293-298)

Keywords: social inequalities; traffic injuries; injury mechanisms; risk exposure

In general terms, the social pattern of injury risks (as that of ill health) is important for at least four reasons. ${ }^{1}$ First, the size of the gap between the mortality and morbidity rates of the most and the least advantaged groups gives some indication of the potential for improvement in a nation's safety and health. Second, identification of groups at greatest risk can influence the sound governance of medical services (tertiary prevention). Third, the magnitude and form of the relationship between injury and social position can suggest hypotheses concerning injury mortality etiology, all causes aggregated or by separate cause. Fourth, better understanding of the mechanisms of social variations in injury risk enables intervention strategies by means of which injuries can be reduced.

Inequalities in mortality and morbidity distribution between social groups are seen in most industrialized countries. Inequalities are also higher among younger age groups, for which injuries account for a great part of mortality and morbidity. ${ }^{2}$ In the industrialized world, traffic injuries, apart from being the most common cause of death among children, adolescents and young adults, are also one of the causes of mortality with the steepest social class gradient. Yet, little is known concerning the mechanisms by which social differences between areas (upstream explanations) and between individuals (downstream explanations) interact in determining traffic injury risks.

The current paper describes a number of possible (and measurable) mechanisms using a model as a frame of analysis of studies concerned with social differences in health. ${ }^{34}$ The model is then used as a frame for presenting the evidence accumulated in the scientific literature concerning social differences in traffic injury in childhood ( $0-15$ years). The main lines of a research agenda are then drawn, emphasizing central study questions.

Literature search and frame of the review In 1997 we conducted a literature review of social inequalities in injury risks by means of an extensive search of 13 international databases (Medline, EMBASE, IAC, HealthSTAR, Pascal, Sociological Abstracts, International Pharmaceutical Abstracts, Social SciSearch, PsycINFO, Social Sciences Abstracts, Scisearch, AMA Journals, Dissertation Abstracts Online). ${ }^{2}$ The key words employed for all searches were "injury or injuries or accident or accidents or suicide or suicides or violence" combined with "social()etiology or inequality or class or status". Additional studies were identified by examining of reference lists in selected articles,
Medicine, SE-171 76

Stockholm, Sweden

(lucie.laflamme@phs.ki.se) 


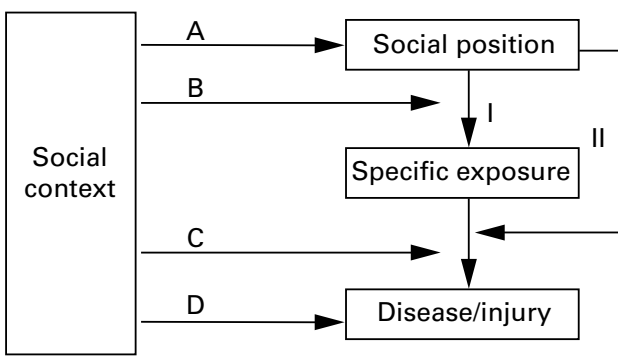

Figure 1 A conceptual framework for studying the impact on injury of social position and social context. ${ }^{3 .}$

and through scrutiny of the 1997 and 1998 issues of peer reviewed scientific journals (BMF, the Lancet, Social Science and Medicine, the American Fournal of Public Health, Injury Prevention, Safety Science, and Accident Analysis and Prevention).

For this paper, we included only empirical studies published in indexed (refereed) international journals and dealing with social differences between individuals (downstream explanations) or areas (upstream explanations) in all categories of traffic injuries in childhood.

We adopted a conceptual framework developed by Diderichsen and Hallqvist ${ }^{3}$ (see also Diderichsen $e t a l^{4}$ ) that integrates downstream and upstream explanations of social differentials in health and safety (as summarized in Laflamme ${ }^{2}$ ) and highlights the manner in which social context and social position may interact, via a number of different mechanisms (see fig 1).

At an individual level, two downstream mechanisms may come into play in the relationship between social position and injury: differential exposure (I) and differential susceptibility (II). Contextual influences are highlighted by four entry points, each of which refers to a different mechanism. Social context is regarded as encompassing interwoven elements in the physical, cultural, social, and economic environments that characterize a neighborhood or society. There are impacts of social context on social stratification (A), on differential exposure (B), on differential susceptibility (C), and directly on health (D). Emphasis is placed on how prevailing physical and social settings interact with and influence the pathways from social position to injury.

In the last part of this paper, the model will be used to draw the main lines of a research agenda. In the text below, it serves as a basis to review the knowledge accumulated so far, presenting in turns the empirical evidence regarding the three main components of the model: social context, social position, and exposures (both transient and latent ones).

\section{Results}

SOCIAL CONTEXT

Most of the reviewed literature considered the spatial distribution of injuries, comparing aggregated social characteristics, for example, by census tract. Two distinct designs were employed: (1) geographic areas were grouped by socioeconomic status and injury rates were compared across socioeconomic groups or (2) areas were grouped by level of injury risk, and socioeconomic characteristics were compared across risk levels. Despite intrinsic conceptual differences between the two approaches, ${ }^{5}$ the findings of both generally suggest that injury risks increase with socioeconomic deprivation. There follow accounts of studies with relevant themes organized under separate subheadings.

\section{Socioeconomic characteristics and differences in} injury risks

Dougherty et al observed that the annual injury rate (fatal and non-fatal injuries) of children (0-14 years) living in the poorest income quintile neighborhoods of Montreal city was four times that of children living in the least poor neighborhoods. ${ }^{6}$ Differences in mortality rates throughout urban Canada did not follow such a consistent and significant pattern, however, although rates were consistently highest in the poorest income quintile. Also, social inequalities in mortality between census tracts were much more pronounced for pedestrians than for bicyclists. These differences were explained largely by differential exposure levels: cyclists from lower social class census tracts perhaps being more likely to venture outside their own (relatively dangerous) neighborhood or local area, whereas young pedestrians are more likely to remain near their home.

In a study in Nottingham (UK), Kendrick also analyzed pedestrian injuries among children under 12, and calculated a zone deprivation score on the basis of low income, unemployment, lack of skills, poor housing, poor health, and family problems. ${ }^{7}$ Zones were categorized into areas of extreme, serious, moderate, and below average disadvantage. The investigators found a significantly higher injury rate in deprived areas, and a doseresponse relationship between degree of deprivation and injury rates.

Injury rates and differences in socioeconomic characteristics

Preston reported that the injury rate for child pedestrians was much higher in some areas of Manchester and Salford (UK) than in others. ${ }^{8}$ She observed that the injury rate correlated with distance of the area from the town center and with an index of social class for the area (but only for boys). She concluded that the differences are due to a lack of safe playspace in unsafe areas.

In a study in Memphis (US), Rivara and Barber observed that census tracts with reported pedestrian injuries had twice the percentage of non-white inhabitants, lower household incomes, more children living in female headed households, more families living below the poverty line, and greater household crowding compared with census tracts without reported injuries. ${ }^{9}$ Crowded housing per acre was the single variable that best predicted the number of injuries per acre.

Another study compared the means of various ecological variables in high and low risk traffic injury areas in Montreal. ${ }^{10}$ The results 
showed that pedestrian injuries had a particular spatial pattern, with high risk zones being characterized by high population density, fast moving traffic, and the absence of parks. Levels of education, income, and housing were significantly lower in the so-called high risk zones. (The same also applied in the case of bicycle related injuries. ${ }^{11}$ )

Similar results concerning pedestrian injuries were obtained in Calgary (Canada). ${ }^{12}$ This study revealed significant correlations between areas with greater pedestrian injury (and crime) rates and percentage of housing with government subsidy, population density, percentage of unemployed, percentage of community space as public park (a negative association), and percentage of persons of low birth weight.

A study in Hartford (US), concerned with pedestrians younger than 15, compared census tracts classified as high frequency, moderate frequency, or low frequency with regard to motor vehicle collisions. ${ }^{13}$ High frequency tracts had greater proportions of children and non-white residents than moderate frequency or low frequency tracts. The former were also characterized by a high proportion of households headed by females living below the poverty line. In addition, high frequency tracts had a greater number of children per acre than moderate or low tracts (see also Preston ${ }^{8}$ ). Children per acre was the variable with the strongest association with collision frequency, and remained the most consistent predictor after controlling for other variables.

Finally, on performing an area analysis of child injury morbidity in Auckland, New Zealand, Roberts et al observed that total injury morbidity, pedestrian injuries, and motor vehicle occupant injuries were strongly correlated with census area unit employment rates. ${ }^{14}$

Other designs for ecological studies

The importance of the environment as a pedestrian injury risk determinant is highlighted in a small scale American study conducted by Mueller et al. ${ }^{15}$ Using a casecontrol design, various environmental and traffic characteristics were assessed after visits to the neighborhoods of all subjects. Children living in multifamily dwellings had 5.5 times greater risk than children living in single family homes. In general, areas with busier streets (greater posted vehicle speeds) and/or greater traffic volumes were associated with increased risk of pedestrian injury.

SOCIAL POSITION

Income (of head of family)

An injury rate that decreased with increasing income (of head of family) was found in a study of children under 20 conducted in Boston (US). ${ }^{16}$ This finding was explained by the fact that low family income in an urban center served as Boston is by major public transit systems may result in relatively lower exposures to private motor vehicle occupancy than in areas where private vehicle ownership may be essential. In the Netherlands, the death rate for motor vehicle occupants was also found to be negatively associated with individual income, whereas that for cyclists was positively associated. ${ }^{17}$

\section{Ethnicity and race}

Ethnic or racial differences in traffic injuries have been studied most frequently in the US. For example, Fingerhut et al observed that, although the black to white ratio was relatively low for passenger fatalities ( 0.8 to 1.2$)$, the ratio for child pedestrian injuries was considerably higher (1.5 to 2.0$){ }^{18}$ Later, OnwuachiSaunders and Hawkins observed that minority groups, particularly Afro-Americans, were disproportionately represented among persons who die as a result of injury in general, and of traffic and pedestrian mishap injury in particular. ${ }^{19}$ Also, black males were over-represented among injury victims of all types.

Agran et al observed that, in southwestern US, Hispanic children have a rate of hospitalization or death from pedestrian injury more than twice as high as that of non-Hispanic white children (after controlling for census block group of residence). ${ }^{20}$

A study that considered injury rates by age (1-5, 6-11, and $12-16$ years) and place of residence compared injury rates of all kinds among children belonging to the following categories: metropolitan white, metropolitan non-white, and non-metropolitan. ${ }^{21}$ The authors observed that motor vehicle injury and drowning were the leading causes of death for nonmetropolitan children in the age group 1-5, and for non-metropolitan and metropolitan white children aged $6-12$ (for metropolitan non-white children aged 12-16, homicide was the leading cause).

\section{Family characteristics}

Several decades ago, Backett and Johnston, in studying child pedestrian road traffic accidents in Belfast, Northern Ireland (4-15 years), found that significantly more illness was reported among accident families than among controls. ${ }^{22}$ There was also an excess of injured children among families reporting more serious diagnoses. This trend was not significant for all families taken together, but was significant for the younger group, that is, for those with children most directly under parental control. A significant excess related to crowding was found only for the younger children. There was a greater frequency both in the unprotected group and among those with (more objectively measured) absence of play facilities (garden, yard, or playroom). Number of sibling size, birth rank, spacing, and age structure of family did not distinguish between victims and controls.

Pless et al highlighted five risk factors related to traffic accidents in childhood, three of which were measures of family disruption or disadvantage: crowding, family problems, and being removed from the family and placed in the care of a local authority. ${ }^{23}$ Of the family factors assessed at age 7 , boys in homes lacking basic amenities were found to be at increased risk of injury. Girls in the two age groups considered (7-11 and 12-16 years) with family problems 
also showed significantly raised odds ratios. In addition, with regard to these same factors assessed at the age of 11 , boys not living with their natural mother and those in either age range who had been taken into the care of the local social services, showed significantly increased risk of injuries.

Higher family stress and lower family supportiveness, as well as crowding in nonblack families, were also found to be significantly more often reported among children aged 5-12 years injured as pedestrians than among controls in a study conducted by Christoffel et al..$^{24}$ Roberts found that sole parenthood was a significant injury risk factor for pedestrian injury in the Auckland region of New Zealand. ${ }^{25}$ However, although sole parenthood was associated with a greatly increased risk of injury among European families, in families from the Pacific islands it seemed to have a significant protective effect.

Focusing on Hispanic children in the southwestern US (0-14 years), Agran et al observed that pedestrian injury risk increased with household crowding, one or more family moves within the past year, poverty, and inability of the mother or father to read. ${ }^{26}$ Other factors, such as being a child in a single parent households, or a child whose parents did not drive a car, had relatively little education, or were of rural origin, were not significantly associated with injury risk.

EXPOSURES

Risk activities

It has been shown that pedestrian injuries in early childhood occur most often near the home. ${ }^{8101123}$ This is not surprising because this is where young children spend most time. Preston observed that young boys (3-7 years) were more likely to be injured while playing than girls (see also Havard ${ }^{27}$ ). ${ }^{8}$ Another study found an increase in injuries among boys was in the fall, because of playing outside in the dark streets but not because of traveling to school. ${ }^{28}$

From another perspective, Roberts and Norton observed that there are considerable socioeconomic and ethnic differences in children's exposure to risk as pedestrians (but not in parental perceptions of risk). ${ }^{29}$ These are reflected in particular in differences in patterns of children's travel to school. The increased pedestrian injury rates found for poor children and some ethnic groups (for Maori and Pacific Island children in New Zealand in this case) may be explained in part by increased exposure. In turn, increased exposure is likely to reflect social and economic constraints rather than differences in perceptions of danger to children as pedestrians.

Behaviors

Backett and Johnston compared a randomly selected group of school aged children who had a pedestrian injury with a control group matched for various personal and family characteristics: family and maternal health, maternal preoccupation, family size and age structure; poverty and prosperity of family, protected and unprotected play, crowding,

\section{Main findings}

- The evidence accumulated so far on social differences in traffic injuries among children suggests that children from lower social positions and in more deprived socioeconomic areas are quite consistently more at risk than others.

- This may apply in varying degrees according to sex, age, and category of traffic injury (pedestrian, motor vehicle passenger, and cyclist).

- So far, the explanation best supported by the evidence is that the social gradient reflects differential exposure of children to various hazards (as opposed to propensity to behave in any particular manner).

other accidents, intelligence. ${ }^{22}$ They observed that neither measured intelligence of the child nor a history of other accidents in the family distinguished significantly between the victim and control. A later study observed that boys seem to accept greater risks than girls in the face of oncoming traffic (for example, when crossing the road) and that they make less use of safe crossings, ${ }^{27}$ a finding in line with those showing that girls are more often injured than boys under these circumstances. ${ }^{8}$

A wide ranging study dealing with child behaviors and traffic injuries was conducted by Pless et al. ${ }^{23}$ When all factors were entered into a final model, only five remained: fidgety, abnormal behavior, and three measures of family disruption or disadvantage. The authors believed the most striking finding to be the paucity of strong predictors. They argue that this suggests that the major risks of traffic injuries among children are not those associated with personal or family characteristics, but rather with environmental factors.

\section{Discussion}

The evidence accumulated so far on social differences in traffic injuries among children suggests that injury mortality and morbidity have non-random individual and spatial distributions. Children from lower social positions and in more deprived socioeconomic areas are quite consistently more at risk than others. This may apply in varying degrees according to sex, age, and category of traffic injury (pedestrian, motor vehicle passenger, and cyclist).

Though the reasons for that are still unclear, the explanation best supported by the evidence is that the social gradient reflects differential exposure of children to various hazards (as opposed to propensity to behave in any particular manner). For those reasons, the mechanisms contributing to social differentials in traffic injury risks deserve greater attention in future research. ${ }^{30}$

MAIN LINES FOR A RESEARCH AGENDA

Injury research still lacks explanatory models for-and data on how-contextual and individual factors, separately and interactively contribute to injury causation. Inspiration can be 
found in the rapidly growing volume of public health research designed to elucidate the role played by people and places in the determination of social differentials in health. ${ }^{3431-35}$ Research of that kind would be of considerable help in understanding the social patterning of exposures to traffic injury and, ultimately, in increasing equity in the benefits of local or national preventive strategies, where it is needed (see an example in Reading et $a^{35}$ ).

Having access to both individual outcomes (for example injuries) and individual and contextual exposures, it is possible to break down the simple ecological relationship between social deprivation and traffic injury rate into specific questions related to mechanisms (see fig 1) and test them empirically. The questions of primary importance as for traffic injuries are summarized below.

Question 1. What is the effect of the social context on injury risks, after controlling for individual effects? (see D in fig 1)

Social context, as defined earlier, constitutes an explanation level per se of injury occurrence, in general, and of traffic injury, in particular. For sure, consideration of the nature and role of context (for example, living area or community) influences is by no means new in safety research. However, scrutiny of the precise meaning of an "area effect", and explicit consideration of how such effects are specified statistically, have been absent from most empirical research into the determinants of safety in populations. It may be that area level variation is unimportant, or that area level variables that explain this variation cannot be found. ${ }^{35}$ But this can only be established, as distinct from being assumed, by employing empirical model specifications that enhance rather than constrain the capacity of a model to reflect the underlying conceptual framework. ${ }^{34}$

Question 2. Are ecological influences due exclusively to characteristics of the people that live in it?

An ecological relationship between, for example, relative deprivation and injury rate might be due to the sum of individual effects, that is quite simply, that poor individuals are at greater risk (see A in fig 1). Segregation on the housing market is a possible socioeconomic engine in this context.

But there are effects other than "compositional" ones that may lie behind the effect of the living context, so-called contextual effects. ${ }^{30}$ Contextual effects operate where the health and safety experience of a particular type of individual depends not only on such individuals' own characteristics but also on the area where they live. Besides the net effects underlined in question 1, contextual factors may interplay by modifying some individual mechanisms, namely differential exposures and differential susceptibility (respectively I and II in fig 1).
Where are we and how could we move forward?

- Injury research still lacks explanatory models for-and data on howcontextual and individual factors, separately and interactively contribute to injury causation. Inspiration can be found in the rapidly growing volume of public health research designed to elucidate the part played by people and places in the determination of social differentials in health.

- Research of that kind would be of considerable help in understanding the social patterning of exposures to traffic injury and, ultimately, in increasing equity in the benefits of local or national preventive strategies, where it is needed.

Question 3. Does the social context modify the degree of differential exposure?

Context related factors may have a protecting impact on differential traffic exposures (see B in fig 1), when traffic separation or a well functioning public transport system eliminate some risks - for the benefit of all.

Question 4. Does the social context have an effect and interact with individual exposures?

It is clear that physical context (in terms of traffic intensity) or a protective arrangement (such as traffic separation or the provision of school transport) will have a strong impact on injury risk. But the social context, in terms of social cohesion or extended family networks, may also play a non-negligible part. In many cases, contextual effects will modify the effects of specific individual exposures (see $\mathrm{C}$ in fig 1). Empirically, such effects will be demonstrated by interaction between area and individual exposure.

\section{Question 5. Do exposures to traffic risk differ} between social groups?

This question can be included in the more general question concerning the amount and pattern of children's activity (current and as it develops over time). As previous studies have shown, there are good reasons to believe that there are differences in the extent to and manner in which children and youth use the streets (for example, transport themselves, play and so on; see I in fig 1). In this context, the "specific exposures" in fig 1 refer to time spent or distance walked in traffic, or to number of transient triggering exposures (for example, poor traffic regulation, control malfunctioning).

Question 6. Are factors modifying the effect of specific exposures related to social position?

Social position influences, for example, degree of parental supervision and other factors that might modify injury risks at a certain level of traffic exposure or transient risk (see II in fig 1). Such differential susceptibility can be tested empirically by analyzing whether specific 


\section{Conclusions}

Socioeconomic differentials in injury risks are neither unavoidable nor irreversible. Indeed, differentials in wealth may not inevitably be reflected in differentials in injury risks. For example, built-in safety and improved designs and environments can do a lot to enhance safety for all. But, when abatement strategies are not possible, making a choice between alternative strategies and means for prevention may require a deeper understanding of the mechanisms via which socioeconomic differentials in injury risks are produced.

exposure (for example, time spent on the streets) and social position interact.

\section{Implications for prevention}

Despite the effort deployed so far to analyze social differentials in traffic injury risks in childhood and youth, and despite the evidence accumulated on how widespread those differences are, the mechanisms responsible for the differences remain poorly understood. To paraphrase Blane, ${ }^{1}$ better understanding of those mechanisms permits adoption of prevention strategies.

Built-in safety and improved designs and environments (for example, a well functioning public transport system or traffic separation) can do much to enhance safety for all. But, when abatement strategies that eliminate, reduce or isolate the risks are not possible, making a choice between alternative strategies and means for prevention requires a deeper understanding of the mechanisms by which socioeconomic differentials in injury risks are produced.

1 Blane D. Social determinants of health. Socioeconomic status, social class, and ethnicity [editorial]. Am f Public Health 1995;85:903-5.

2 Laflamme L. Social inequality in injury risks. Accumulated knowledge and strategies for the future. Stockholm: National Institute of Public Health, 1998: 33.

3 Diderichsen F, Hallqvist J. Social inequalities in health: some methodological considerations for the study of social
position and social context. In: Arve-Parés B, ed. Inequality position and social context. In: Arve-Pares B, ed. Inequality in health-a Swedish perspective.

4 Diderichsen F, Laflamme L, Hallqvist J. Understanding the mechanisms of social differences in injuries. In: Laflamme $\mathrm{L}$, Svanström L, Schelp L, eds. Safety promotion research. A public health approach to accident and injury prevention. Stockholm: Karolinska Institutet, Department of Public Health Sciences, 1999: 177-201.

5 Berkman LF, Macintyre S. The measurement of social class in health studies: old measures and new formulations. In: Kogevinas M, Pearce N, Susser M, et al, eds. Social inequalities and cancer. Lyon: International Agency for Research on Cancer. IARC Scientific Publications No 138, 1997.
6 Dougherty G, Pless IB, Wilkins R. Social class and the occurrence of traffic injuries and deaths in urban children. Can F Public Health 1990;81:204-9.

7 Kendrick D. Prevention of pedestrian accidents. Arch Dis Child 1993;68:669-72.

8 Preston B. Statistical analysis of child pedestrian accidents in Manchester and Salford. Accid Anal Prev 1972;4:32332.

9 Rivara FP, Barber M. Demographic analysis of childhood pedestrian injuries. Pediatrics $1985 ; 76: 375-81$.

10 Joly MF, Foggin PM, Pless IB. Les déterminants socioécologiques du risque d'accident du jeune piéton. Rev Epidém et Santé Publ 1991;39:345-51.

11 Joly MF, Foggin PM, Zvagulis I, et al. Bicycle accidents among children in the urban environment. Can $\mathcal{F}$ Public Health 1989;80:351-4.

12 Bagley $\mathrm{C}$. The urban setting of juvenile pedestrian injuries: a study of behavioural ecology and social disadvantage. Accid Anal Prev 1992;24:673-8.

13 Braddock M, Lapidus G, Gregorio D, et al. Population, income, and ecological correlates of child pedestrian injury. Pediatrics 1991;88:1242-7.

14 Roberts I, Marshall R, Norton R, et al. An area analysis of child injury morbidity in Auckland. $\mathcal{F}$ Paediatr Child Health 1992;28:438-41.

15 Mueller BA, Rivara FP, Lii SM, et al. Environmental factors and the risk for childhood pedestrian-motor vehicle collision occurrence. Am f Epidemiol 1990;132:550-60.

16 Wise PH, Kotelchuck M, Wilson ML, et al. Racial and socioeconomic disparities in childhood mortality in Boston. N Engl f Med 1985;313:360-6.

17 van Beeck E, Mackenbach JP, Looman CWN, et al. Determinants of traffic accident mortality in the Netherlands: a geographical analysis. Int 7 Epidemiol 1991; 20:698-706.

18 Fingerhut LA, Kleinman JC, Malloy MH, et al. Injury fatalities among young children. Public Health Rep 1988;103: 399-405.

19 Onwuachi-Saunders C, Hawkins DF. Black-white differences in injury. Race or social class? AEP 1993;3:150-3.

20 Agran PF, Winn DG, Andersson CL. Pediatric injury hospitalization in Hispanic and non-Hispanic white children in Southern California. Arch Pediatr Adolesc Med 1996;150: 400-6.

21 Singh GK, Yu SM. US childhood mortality, 1950 through 1993: trends and socio-economic differentials. Am F Public Health 1996;86:505-12.

22 Backett EM, Johnston AM. Social patterns of road accidents to children: some characteristics of vulnerable families. BMF 1959;i:409-13.

23 Pless IB, Peckham CS, Power C. Predicting traffic injuries in childhood: a cohort analysis. F Pediatr 1989;15:932-8.

24 Christoffel KK, Donovan M, Schofer J, et al. Psychosocial factors in childhood pedestrian injury: a matched casecontrol study. Pediatrics 1996;97:33-42.

25 Roberts I. Sole parenthood and the risk of child pedestrian injury. F Paediatr Child Health 1994;30:530-2.

26 Agran PF, Winn DG, Andersson CL. Family, social, and cultural factors in pedestrian injuries among Hispanic children. Inj Prev 1998;4:188-93.

27 Havard JDJ. Child pedestrian casualties as a public health problem. Med Sci Law 1974;14:168-79.

28 Sunderland R. Dying young in traffic. Arch Dis Child 1984; 59:754-7.

29 Roberts I, Norton R. Auckland children's exposure to risk as pedestrians. N Z Med f 1994;107:331-3.

30 Duncan C, Jones K, Moon G. Context, composition and heterogeneity: using multilevel models in health research. Soc Sci Med 1998;46:97-117.

31 Kaplan GA. People and places: contrasting perspectives on the association between social class and health. Int $\mathcal{F}$ Health Services 1996;26:507-19.

32 Shouls S, Congdon P, Curtis S. Modelling inequality in reported long term illness in the UK: combining individual area characteristics. F Epidemiol Community Health 1996; 50:366-76.

33 Diez-Roux AV. Bringing context back into epidemiology: variables and fallacies in multilevel analysis. Am F Public Health 1998;88:216-22.

34 Birch S, Stoddart G, Béland F. Modelling the community as a determinant of health. Revue Canadienne de Santé Publique 1998;89:402-5.

35 Reading R, Langford IH, Haynes R, et al. Accidents to preschool children: comparing family and neighborhood risk factors. Soc Sci Med 1999;48:321-30. 